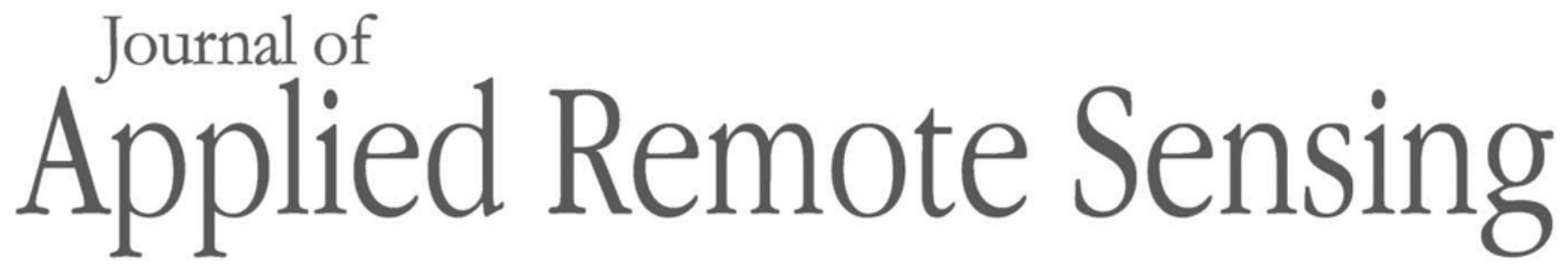

RemoteSensing.SPIEDigitalLibrary.org

\title{
Assessing seasonal land cover dynamics in the tropical Kilombero floodplain of East Africa
}

Fridah Kirimi

Kuria Thiong'o

Geofrey Gabiri

Bernd Diekkrüger

Frank Thonfeld 


\title{
Assessing seasonal land cover dynamics in the tropical Kilombero floodplain of East Africa
}

\author{
Fridah Kirimi,* Kuria Thiong'o, Geofrey Gabiri, Bernd Diekkrüger, and \\ Frank Thonfeld \\ University of Bonn, Department of Geography, Bonn, Germany
}

\begin{abstract}
Increasing demand for food in East Africa has created a shift to utilize wetlands for food production. Lack of spatial information hampers sustainable use of the Kilombero Valley floodplain. We take advantage of multispectral data from RapidEye, Landsat-8, and Sentinel-2 to derive high temporal resolution maps along three hydrological zones of the Kilombero Valley, assess seasonal land cover dynamics, and relate these dynamics to groundwater measurements. The depth of groundwater increases from June and declines from December, consistent with the end and the beginning of the rainy season, respectively. Bare land cover over the study area was $45 \%$ to $57 \%$ and increases to $62 \%$ to $69 \%$ as the season shifts from rainy to dry seasons while vegetation coverage, which was $34 \%$ to $47 \%$, decreased to $25 \%$ to $27 \%$. During the dry season, $68 \%$ to $81 \%$ of the total vegetation is within the riparian zone indicating the hydrological conditions favor plant growth. Vegetation growth in the fringe and middle zones mainly relies on precipitation whereas that in the riparian zone relies on saturation from the river. Our findings exemplify the relationship between seasonal land cover change and hydrological conditions and contribute to improved understanding of the spatial-temporal land cover dynamic in the Kilombero floodplain, required for planning sustained use of the wetland. (C) The Authors. Published by SPIE under a Creative Commons Attribution 3.0 Unported License. Distribution or reproduction of this work in whole or in part requires full attribution of the original publication, including its DOI. [DOI: 10.1117/1.JRS.12.026027]
\end{abstract}

Keywords: wetlands; RapidEye; Landsat-8; Sentinel-2; cumulative season maps; depth to groundwater; food security.

Paper 180199 received Mar. 10, 2018; accepted for publication May 18, 2018; published online Jun. 7, 2018.

\section{Introduction}

Sub-Saharan Africa is expected to account for $20 \%$ of the world population by $2050 .{ }^{1}$ Land therefore remains under increasing pressure driven by urbanization and population growth. Subsequently, the need for land to expand agricultural production has led to deforestation and encroachment in protected areas such as wetlands, negatively affecting the regulatory functions of the ecosystem. In addition, agricultural production systems are adversely affected by climate variability and climate change causing extreme weather events (increase of amount and variability of rainfall and increase of temperature) and changing seasons. ${ }^{2-4}$ Low crop productivity due to water stress and degradation of soil fertility is among the consequences of the changing climate.

Tanzania is an agricultural country with $80 \%$ of the population depending on subsistence agriculture. ${ }^{5}$ Kilombero Valley was identified as a potential agricultural area to enhance food security and meet the SDG $2 .^{6-8}$ A large seasonally flooded alluvial floodplain is within the Kilombero Valley. Expansion of agricultural land in the floodplain is restricted due to the existence of protected areas, i.e., the Kilombero Game Controlled Area, the Selous Game Reserve, and the Udzungwa National Park. Furthermore, changing climatic patterns affects agricultural production causing extreme periods of dryness, floods, and changes in seasonality.

*Address all correspondence to: Fridah Kirimi, E-mail: fridahkirimik@gmail.com 
The increasing demand for food, shortage in arable land, and unpredictable climate conditions in East Africa have recently created a shift from upland cultivation to Kilombero Valley. This highlights the need for wetland monitoring and the generation of seasonal land cover maps for sustainable conservation policies. ${ }^{9,10}$ Within the study area, few studies on the status of the wetlands exist. Monitoring spatial phenomenon through ground survey method is tedious and not cost effective. With their synoptic view, spectral and temporal capabilities of remote sensing sensors provide an alternative timely and cost-effective method of data acquisition.

Remote sensing of wetlands in East Africa has had a long history of study. The evaluation of vegetation dynamics at regional scale over East Africa with Advanced Very High Resolution Radiometer (AVHRR) data for 1983 to 1984 revealed that NDVI is suitable in determining phenology in areas of high spatial variability. ${ }^{11}$ Haack ${ }^{12}$ reported an increase in sedimentation and decreased water levels in Lake Turkana due to increased agriculture and livestock farming between the years 1979 and 1989. AVHRR was applied in assessing the land cover changes in Mara National Reserve ecosystem in Kenya for the periods between 1981 and 1994. Reports indicated that expansion of agriculture within the buffer of the national park has resulted in decreased vegetation though the reserve is stable in terms of land cover changes since it is a protected area. ${ }^{13}$ Within the Lake Baringo catchment in Kenya, pressure due to increasing human livestock population was reported to cause reduction in forested areas and increased sediment deposition between 1986 and 2000. ${ }^{14}$

More recently however, within the Kilombero Valley, land cover change was assessed by Ntongani et al. ${ }^{15}$ using local knowledge. From their research, the local population reported a conversion of forested areas and grasslands to cultivated areas for a period of more than 30 years. Recently, Leemhuis et al. ${ }^{16}$ analyzed long-term land changes (1994 to 2004 and 2004 to 2014) in the whole Kilombero Valley while Seki et al. ${ }^{10}$ assessed land cover changes (1990, 1998, and 2011) in the Kibasira Swamp in the Kilombero Valley with both studies revealing an increase in agricultural land. While these studies cover periods between 8 and 13 years, they are relevant in portraying the long-term changes. The land cover dynamic within 1 year is important for determining the suitable cropping seasons in this rainfed agricultural region. Understanding the land cover dynamics will therefore aid in recognizing the shortterm land use patterns subsequently promoting monitoring programs to ensure sustainable use of the wetland to increase agricultural production. ${ }^{17,18}$ Furthermore, to our knowledge, there is no published work on land cover mapping at high temporal resolutions over East African wetlands. Knowledge on seasonal land cover is important to farmers as it aids in understanding the patterns experienced throughput the year within the wetland and hence aid in identification of times and locations with optimum vegetation growth.

Groundwater provides base flow for rivers, dilutes effluents, and is a source of water for domestic and commercial uses. ${ }^{19}$ A strong feedback between groundwater and land use exists influencing water availability for plants and groundwater recharge. ${ }^{20-23}$ With changing climate, the value of groundwater is expected to increase to sustain agriculture and domestic use needs. ${ }^{24}$ A review of land cover relation to groundwater in Ref. 25 revealed a need for site-specific groundwater monitoring networks due to the highly varied environmental and geological landscapes of Africa. The importance of the land use-groundwater relation is emphasized due to the increased demand for water to meet the needs of the rising population. ${ }^{25}$

In this study, analysis of multispectral imagery (RapidEye, Landsat, and Sentinel-2 images spanning from 2013 to 2016) was conducted to map seasonal land cover variability. The selected optical images played complimentary roles as RapidEye has a high spatial resolution but is costly while Sentinel-2 and Landsat-8 data are both freely accessible. Landsat, however, has a longer time series compared to Sentinel-2, which was launched in 2015. First, RapidEye images were selected due to the availability of the red edge band capable of detecting drastic reflectance changes in vegetation. ${ }^{26,27}$ The open access, free of charge, and consistent availability of European Space Agency's high-resolution Sentinel-2 images favored their selection as the second set of imagery for the study. The subhumid wetland lies in a tropical region experiencing the presence of clouds exacerbated during the rainy season witnessed from March to May. To address the problem of cloud coverage, the third set of images used was Landsat- 8 to densify the acquisitions acquired over the study area despite their lower spatial resolution. 
The supervised nonparametric statistical learning technique support vector machine (SVM) was applied in the land cover characterization. ${ }^{28}$ The concept of SVM is the generation of hyperplanes that best differentiate the input features. Learning involves iterative selection of optimal boundaries minimizing the misclassification. SVMs ability to give good accuracies despite limited training samples prompted its use for the research ${ }^{28,29}$ Moreover, the ability to define kernels and to map the raw data into higher dimension space thus increasing separability between classes favored the use of SVM over other classification algorithms. ${ }^{30}$

In addition to mapping seasonal land cover dynamics, other vegetation dynamics explanatory variables such as depth to groundwater and meteorological conditions are assessed. ${ }^{31}$ The information obtained is important in understanding spatiotemporal patterns of water availability that drive plant growth.

The specific objectives of this study are:

- To assess seasonal land cover changes using multitemporal multispectral satellite imagery with an aim of understanding how land cover reflects the impact of water balance components.

- To generate cumulative seasonal land cover maps.

- To evaluate the temporal patterns of precipitation and spatiotemporal patterns of land cover and their relationship to depth to groundwater along the hydrological zones of a floodplain.

\section{Materials and Datasets}

\subsection{Study Area}

The Ifakara study site is located in an alluvial fan within the Kilombero Valley in Tanzania (Fig. 1) with a coverage of $13 \mathrm{~km} \times 5 \mathrm{~km}$. The study area was chosen because of the high variability of water tables with extensive flooding during the rainy season, subsequent land use patterns, ${ }^{32}$ and its location within the study area of the project GlobE Wetlands of East Africa. ${ }^{33}$ Moreover, the alluvial fan at Ifakara study site acts as a natural dam that retains water during the rainy season. To the north west of Ifakara are the Udzungwa Mountains and to the south are the Mahenge Highlands. Natural forests cover the slopes of the Udzungwa and Mahenge mountains. The region experiences bimodal rainfall with an annual rainfall of 1200 to $1400 \mathrm{~mm}$ and a mean annual temperature of $23^{\circ} \mathrm{C}$ to $25^{\circ} \mathrm{C} .^{34}$ The main subsistence farming practiced in the area includes maize in relatively dry conditions and rice in naturally inundated areas. Both largeand small-scale farmers practice sugarcane farming. Fishing is an important economic activity, which provides food and a source of livelihood for the local population. Forest products, brick making, and livestock keeping are among other economic activities taking place in the wetlands. ${ }^{35}$ The Kilombero Valley is also an important tourist destination for those visiting the Udzungwa National Park, the Mikumi National Park, and the Selous Game Reserve.

The hydrological zones were subdivided based on extent and duration of flooding during the long rainy season. ${ }^{36}$ The fringe zone is not flooded; the middle zone is flooded on a regular basis, whereas the riparian zone is completely flooded during the long rains. The riparian fields are located closest to the Kilombero River, the middle fields located between riparian and fringe fields have elevation slightly higher than the riparian fields, and the fringe fields are located furthest from the river at a higher elevation compared to the other two test sites. Elevation increases with increasing distance from the river. Subsequently, the flooding depths are higher in the riparian zone. This is important as planting rice in the riparian zone implies the risk of drowning the crops.

\subsection{Datasets}

\subsubsection{Satellite data}

The multispectral data used in this study comprised of two high-resolution (RapidEye and Sentinel-2) and the medium resolution (Landsat) imagery (Fig. 2). Classification was performed on each individual image to generate a series of land cover maps on the dates of image 

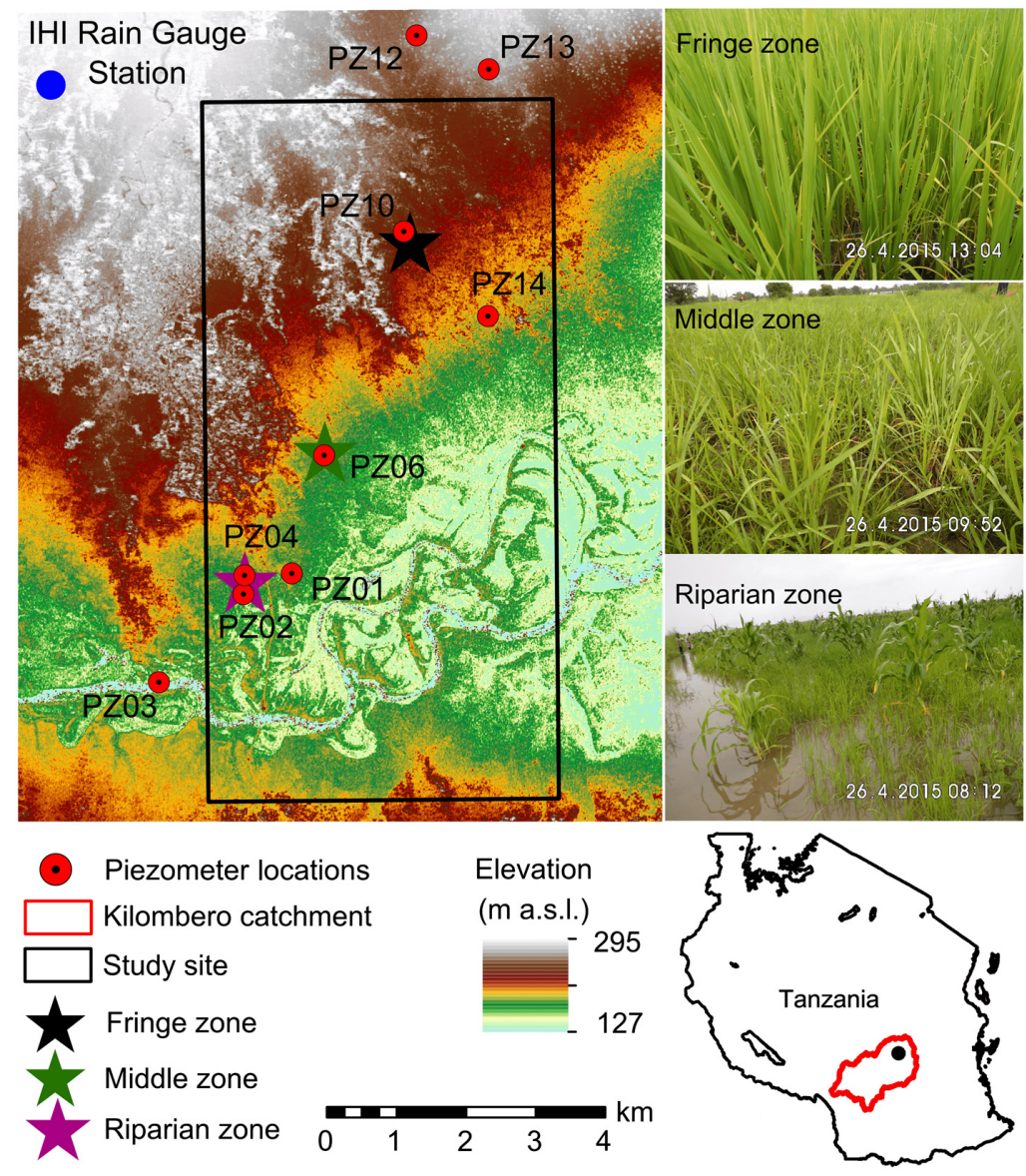

Fig. 1 Location of the Ifakara study site within the Kilombero Valley, Tanzania. The riparian, middle, and fringe zones are hydrological zones categorized based on the flooding pattern during the rainy season. Elevation information, piezometer (PZ) locations, and corresponding study site photos taken April 26, 2015. The location of the rain gauge installed at IHI is indicated as blue spot.

acquisition. RapidEye has five spectral bands with at nadir pixel resolution of $6.5 \mathrm{~m} \times 6.5 \mathrm{~m}$ resampled to $5 \mathrm{~m} \times 5 \mathrm{~m}$. The data acquired from Ref. 37 were level $1 \mathrm{~B}$ in which the radiometric and sensor corrections have been applied. RapidEye images have a resolution of $5 \mathrm{~m}$ for all bands hence no resampling was applied. Fourteen level 1B RapidEye scenes from August 2013 to June 2015 were analyzed.

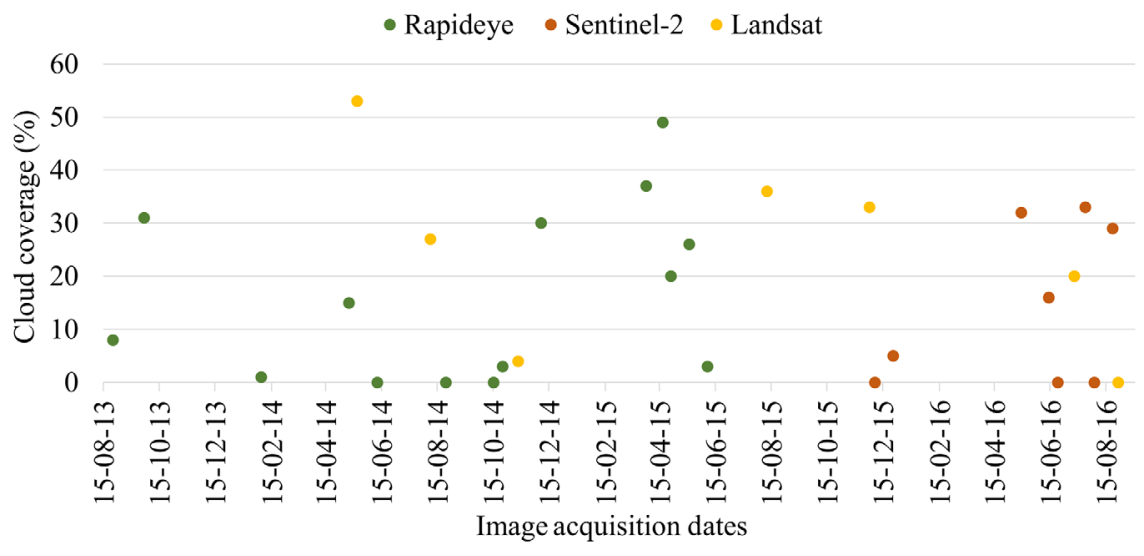

Fig. 2 Temporal distribution of the RapidEye, Landsat, and Sentinel-2 image acquisitions. Percentage of cloud coverage of the images is indicated. 
Nine Sentinel-2 images were downloaded from Ref. 38. The images have a spatial resolution of $10 \mathrm{~m}$ with acquisitions from December 2015 to August 2016. Sentinel-2 has 13 bands that include aerosol detection bands, vegetation classification bands, water vapor, and cloud discrimination bands. ${ }^{39}$ In this research, bands 2 to 8 designed for vegetation classification were utilized. Sentinel-2 bands 2, 3, 4, and 8 have a 10-m resolution while bands 5, 6, 7, and 8A have a 20-m resolution. Nearest neighbor resampling was performed on the $20-\mathrm{m}$ bands to obtain an image with uniform 10-m resolution.

Seven Landsat images were downloaded from the USGS Earth Explorer platform. ${ }^{40}$ For the period spanning 2013 to 2016, bands 2 to 8 were used in the analysis as the other images had a big cloud coverage. Landsat Operational Land Imager multispectral bands 1 to 7 have 30-m spatial resolution whereas panchromatic band 8 has a resolution of $15 \mathrm{~m}$. Nearest neighbor resampling was performed on the $15-\mathrm{m}$ band for uniformity in the Landsat bands. Resampling to a higher and common pixel size for the three sets of imagery would introduce a smoothing effect and a subsequent loss of spatial accuracy and the ability to discriminate features. The spectral properties of the bands in the classification are presented in Fig. 3. ${ }^{39,41,42}$

The spectral band selection (visible, near-infrared, short wave infrared) is reported to be optimal bands in wetland mapping due to their spectral response on the electromagnetic spectrum. The strong reflectance in the red edge and near-infrared related to plant biochemical properties are suitable for mapping vegetation. ${ }^{43}$

\subsubsection{Ground data collection}

Study design. During the data collection campaigns, the fields had rice plantations with varying plant heights (Fig. 1). The plantation in the fringe had heights of 1 to $1.5 \mathrm{~m}$, the middle between 0.5 and $1 \mathrm{~m}$ while the lowest heights were in the Riparian ranging from 0.3 to $0.7 \mathrm{~m}$. Plantations in the riparian fields were submerged by floods to a height of $0.5 \mathrm{~m}$. Scattered maize plantations were also present in the riparian fields.

Training and validation data. Knowledge of study area, false color composition (FCC), and NDVI images generated from the optical images formed the basis of generation of the training and validation points. Utilization of images collected in the past with no corresponding field data and nonaccessibility of some areas within the wetland necessitated the inclusion of NDVI and FCC in the identification of land cover class. FCC used for clear identification of the classes

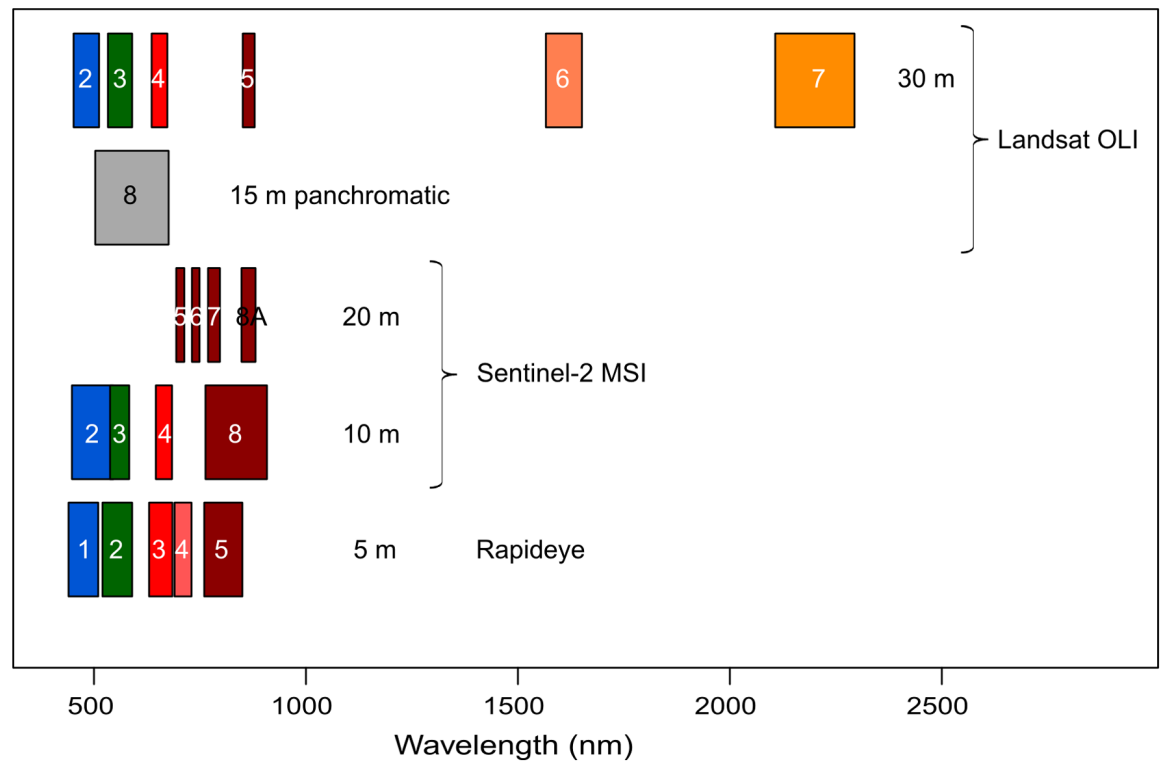

Fig. 3 Attributes of the spectral bands of the sensors used in the classification of the wetland. OLI, operational land imager; MSI, multispectral instrument. 
under study was NIR:R:G, hence for RapidEye 5:3:2, for Sentinel 8:4:3, and for Landsat 5:4:3. Land cover type auxiliary information from global positioning system (GPS) data (March to May 2015 and December 2015 to February 2016) and unmanned aerial vehicle (UAV) photos (May and September 2014 and February 2015) were collected to create a database for generating the training and validation data for the 2013 to 2016 thematic maps.

A LumixGX 1 camera was mounted on an UAV and the MaVinci Desktop software was used for flight planning. The flight periods were May 29 to June 1, 2014, September 24 to 26, 2014, and the last flight campaign was from February 27 to March 2, 2015. Postprocessing of the geotagged UAV photos was performed with the Agisoft PhotoScan software.

Training and validation sample points identifying the land cover classes were determined with the Garmin Etrex 30 GPS with horizontal positional accuracy of $<3 \mathrm{~m} .{ }^{44}$ Points located in a clouded area on the images were removed. Acquisition time for the satellite images, the GPS points, and the UAV photos varied. Field data points were directly obtained from GPS points and others selected from UAV photos close to an image acquisition. Random sampling divided the points into training (70\%) and validation (30\%). However, in some cases, there was no field data (GPS points or UAV flights) corresponding or taken close to image acquisition date while other areas were inaccessible. Hence, NDVI was computed and random sampling performed on the each of the NDVI images to generate 80 to 150 reference points. The sampling design tool on ArcGIS 10.3.1 randomly subdivided these points into training (70\%) and validation (30\%). Therefore, $\sim 2 / 3$ (50 to 100) and 1/3 (25 to 50) points were available for training and validation, respectively. In such cases, inference from NDVI ranges, FCC and local knowledge of the study area were used in identifying the land cover classes.

Monitoring depth to groundwater. Despite the large size of the Kilombero Valley, the study site focused on a small area over which the piezometers were installed. Depth to groundwater was monitored hourly by pressure sensors installed in 10-cm-diameter piezometers at each hydrological position from March 2015 to June $2016 .{ }^{45}$ This research included observations from nine piezometers (Fig. 1). Piezometers 1, 2, and 4 were located in the riparian zone, piezometer 3 was located a few meters from River Kilombero, piezometer 6 was in the middle zone, and piezometers 10 and 14 in the fringe zone while piezometers 12 and 13 were located on higher regions above the study site. In addition to monitoring depth to groundwater, a rain gauge station (Fig. 1) installed at the Ifakara Health Institute (IHI) within the floodplain provided daily precipitation data.

\section{Methods}

\subsection{Work Flow for Satellite Image Processing}

The RapidEye images were orthorectified using the 1-arcsecond Shuttle Radar Topography Mission Digital Elevation Model (SRTM DEM) to ensure they are located in their corresponding $x$ and $y$ locations. The orthorectification was performed in Erdas imagine inbuilt rational polynomial coefficients that relate image and ground coordinates taking into account the satellites orbital position. Atmospheric correction (ATCOR) model removes the influence of the atmosphere, solar illumination, sensor viewing geometry, and terrain information from optical images in the extraction of physical earth surface parameters. ${ }^{46}$ This is important especially when comparison of images acquired from different satellite sensors is required. Atmospheric correction implemented with ATCOR 2 in Erdas imagine applies for multispectral imagery acquired over flat terrain. Bidirectional reflectance distribution (BRDF) defines the reflectance of a target as a function of Sun and sensor viewing geometry. The BRDF effect is reported to have impacts on reflectance.$^{47}$ In small, flat areas with undulating topography, however, the BRDF effect is small as differences in illumination are negligible and therefore BRDF correction was not applied since our study site is $13 \times 5 \mathrm{~km}$ with an elevation difference of $\sim 170 \mathrm{~m}$ (Fig. 1). ${ }^{48}$

Cloud coverage greatly affects optical imagery over the tropical region (Fig. 2). Cloud removal process involved setting thresholds of brightness, second, selecting of areas identified 
as either clouds or cloud shadows was performed by application of the thresholds, third, generating masks from the cloud and cloud shadow layer, and finally, clipping the RapidEye images to eliminate the cloud areas. Cloud masking of top of atmosphere Sentinel-2 and Landsat was performed using the F-mask. ${ }^{49}$ Orthorectification and coregistration followed in the processing chain. Ground control points and Google Earth images were references for the coregistration implemented by autosync tool in Erdas imagine assessed. The positional accuracies were $<2 \mathrm{~m}$ for the Sentinel-2 and $<5 \mathrm{~m}$ for Landsat. Clipping to the size of the study area extent, $13 \times 5 \mathrm{~km}$ as shown in Fig. 1 was the final step in preprocessing.

\subsection{Classification}

SVM is a supervised machine-learning algorithm that separates classes by generating hyperplanes for optimal class separation. The method was selected as it has resulted in high accuracies in monitoring wetland dynamic..$^{50,51}$ The radial basis function that fits data in a higher dimensional space to increase class separability was implemented in EnMap toolbox. ${ }^{52}$ All optical images were classified individually using the training data after which performance metrics were assessed by computing the overall and Cohen's-Kappa coefficient. ${ }^{53}$ Separation of training and validation points offered an independent unbiased accuracy assessment. Figure 4 shows the processing chain of the optical images.

The analysis was as follows:

- SVM classification algorithm was run on the series of multispectral images: RapidEye, Sentinel-2, and Landsat. Built up areas, bare land, vegetation cover, and water extent coverage were the classes of interest. The tropical region is vastly affected by clouds thus a separate class of all masked out areas was included. The total area of classification was 5000 ha. The sensing period for the RapidEye ranged from August 2013 to June 2015 and for Sentinel-2 from December 2015 to August 2016. To increase the temporal resolution of the time series, cloud-free and minimum-clouded Landsat images acquired within the 3 -year study period were included in land cover mapping. The RapidEye, Sentinel-2, and Landsat 5-, 10-, and 30-m resolution were retained for the classification as resampling to a higher pixel size will lower the classification accuracy. ${ }^{54}$

- The validation dataset was used to calculate overall and Kappa coefficient as accuracy assessment tests for the classification. The overall accuracy is the percentage of correctly classified pixels divided by the total number of test pixels. The Kappa coefficient estimates the error reduction generated by the classier verses the error of a random classifier. ${ }^{53}$ It is given as

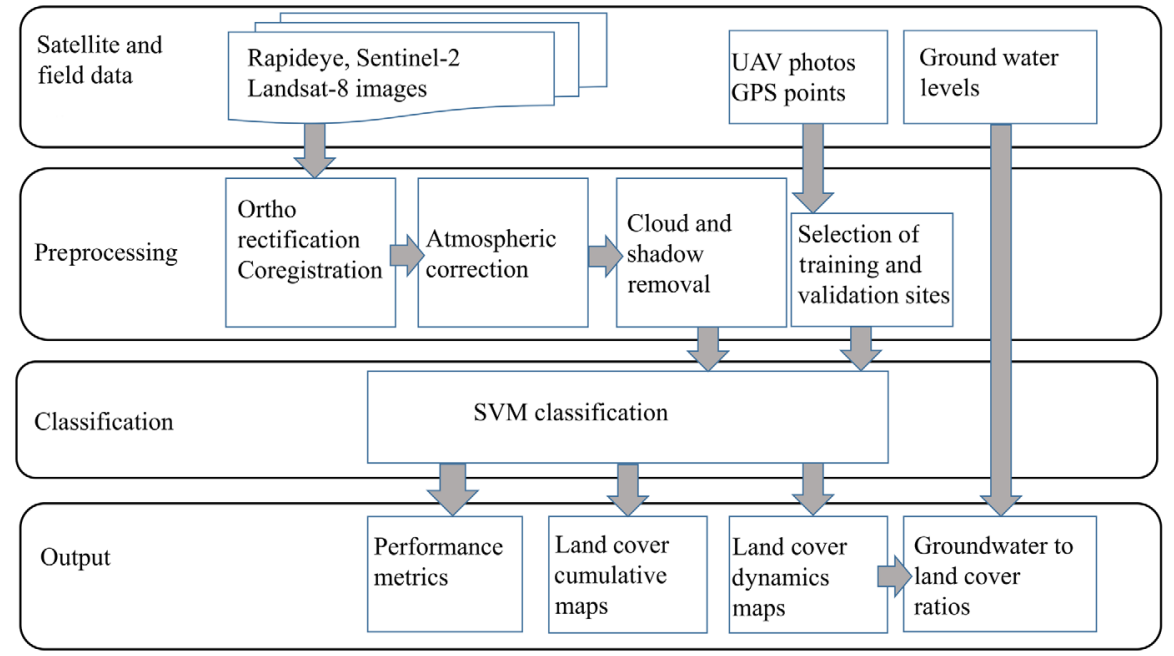

Fig. 4 Data process flow. Auxiliary training and validation points for the SVM classification were obtained using the UAV photos and the GPS points. 


$$
\hat{K}=\frac{p_{c}-p_{e}}{1-p_{e}},
$$

in which $\hat{K}$ is the Cohen's-Kappa coefficient, $p_{c}$ is the correct classification giving the observed level of agreement, and $p_{e}$ is the expected agreement by chance.

- Cumulative seasonal land cover maps were generated from all the classified images to identify the spatial distribution of the most frequent classes over the study area. The spatial resolution of the classified RapidEye images was $5 \mathrm{~m}$, Sentinel- 2 was $10 \mathrm{~m}$, and Landsat was $30 \mathrm{~m}$. All the maps were resampled to a common resolution of $5 \mathrm{~m}$. Resampling to the smallest resolution ensured that the classes assigned to the pixels are retained since the bigger pixels in Landsat and Sentinel-2 are subdivided into smaller sizes. The resampled classified maps were separated into individual classes, i.e., bare, water, vegetated, and built-up. A stack was generated for each land cover class. The number of occurrence of each class through the stacked image was then calculated. This gave the frequency of detection of the given class presented as the cumulative seasonal maps, whose resolution is $5 \mathrm{~m}$. The study selected images taken between January and June (time epoch 1 in the rainy season) and July and December (time epoch 2 in the dry season) in generation of the frequency maps.

- Groundwater levels were qualitatively related to land cover as an additional validation method explaining the occurrence of land covers and groundwater levels in the dry and wet seasons. Ratios generated were constrained to one such that bare ratio + vegetated $_{\text {ratio }}+$ water $_{\text {ratio }}+$ builtup $_{\text {ratio }}=1$.

- The percent land cover within the riparian zone was computed as follows:

$$
\begin{aligned}
& \text { percentage land cover }(x) \text { within riparian zone } \\
& \quad=\frac{\text { land cover }(x) \text { in the riparian zone }}{\text { total land cover }(x) \text { in the whole study region }} \times 100 \text {. }
\end{aligned}
$$

\subsection{Geostatistical Analysis of Depth to Groundwater}

A limited number of piezometers observations provided groundwater levels information. To obtain values for all areas in the study site, the piezometer readings were used in generation of groundwater surfaces. For interpolating the groundwater level measurements, a number of methods are available from which geostatistical methods are the most sophisticated approaches as they analyze the spatial structure of the data. This involves estimation and modeling of spatial correlation (covariance or semivariance) $)^{55,56}$ of measured point data. The average squared difference of data points separated by lag distance $h$ defines the semivariance $\gamma(h)$.

$$
\gamma(h)=\frac{1}{2 N(h)} \sum_{i}^{N(h)}\left\{\left[z\left(s_{i}\right)-z\left(s_{i}+h\right)\right]^{2}\right\},
$$

where $N(h)$ is the number of pairs of observations separated by distance $h, z\left(s_{i}\right)$ is the measured value at $s_{i}$, and $z\left(s_{i}+h\right)$ is the measured value at $s_{i}+h$.

The exponential variogram was fitted

$$
\gamma(h)=\left\{\begin{array}{cc}
0 & h=0 \\
C 0+C 1\left(1-e^{-h / a}\right) & h>0
\end{array}\right.
$$

where $C 0 \geq 0$ is the nugget variance and $C 1$ is the structural variance $(C 1 \geq C 0), C 0+C 1$ is the sill, and $a$ is the range.

The nugget variance represents the small-scale variation due to random factors whereas the sill gives an indication of the total variance of the system. The sill consists of the random and structural variance. Structural variance can be caused by intrinsic factors such as climate, parent material, topography, and soil type. ${ }^{57}$ The degree of spatial dependence indicates the level of correlation between the measured point data different spatial locations 


$$
\text { degree of spatial dependence }=\frac{C 0}{C 0+C 1} .
$$

A spatial dependence $<25 \%$ indicates a strong spatial correlation between the groundwater levels measured at different locations, $25 \%$ to $75 \%$ describe a moderate correlation, and a value $>75 \%$ indicates a weak spatial dependence. ${ }^{58}$ Monthly groundwater raster maps were generated for the period under study.

\section{Results and Discussion}

\subsection{Time Series of Land Cover Characterization Using Multisource Imagery}

The SVM classification algorithm was applied to multitemporal multispectral RapidEye, Sentinel-2, and Landsat satellite imagery (Figs. 5 and 6). The overall classification accuracies for the RapidEye, Sentinel-2, and Landsat ranged from $70 \%$ to 96, and the Cohen's-Kappa coefficients ranged from 0.61 to 0.95 (Table 1).

Despite the varying spatial resolution for Landsat $(30 \mathrm{~m})$, Sentinel-2 $(10 \mathrm{~m})$, and RapidEye $(5 \mathrm{~m})$, the overall accuracies were all above $70 \%$. The potential of each of the satellite sensors in delineating bare, vegetated, water, and urban areas portrays its use in inventorying and monitoring land cover over the study area. The probability that the locations with bare, vegetated, urban, and water on the ground are correctly classified in the map (user accuracy) ranged from 0.48 to 1 , 0.55 to $1,0.83$ to 1 , and 0.64 to 1 , respectively. The probability that the bare, vegetated, urban, and water in the classified map is well represented on the ground (producer accuracy) ranged from 0.5 to $1,0.33$ to $1,0.93$ to 1 , and 0.4 to 1 , respectively. The highest user and producer accuracies were for the vegetated and water classes. There was confusion in identification of the urban and bare classes attributed to building material of many buildings made from earthen bricks. Many roads are also earth roads and hence delineating those from the bare fields presented a challenge. The maps developed show temporal changes in land cover patterns providing seasonal change information for land use planning. Different climate-smart technologies can be adopted depending on the spatial seasonal patterns from the land cover maps and time of year.

The current study was limited to general land cover classes and did not assess crop type mapping. The major challenge was the small sizes of the farms having varying crop types. Object-based classification offers a solution to crop type and field-scale mapping. However, it would require very high-resolution imagery capable of delineating the actual field boundaries.

The use of different sensors with slightly varying number of spectral bands and range is a possible cause of error in classification (Fig. 3). To minimize further differences and likely bias in the data acquired from the three satellite sensors, the same classification algorithm was performed on each individual image. The interpretation of each image is independent of the subsequent images. Varying spatial resolution introduces uncertainties particularly for the Landsat 30-m resolution images. High-resolution satellite imagery is preferable for classification of small sites with small and heterogeneous field sizes and small features present like in the current study. ${ }^{54}$ Features with sizes smaller than the low Landsat resolution pixels were not distinguishable.

The bare cover class is $>70 \%$ in the months of August to October, which coincides with the dry season. It is a common practice for the farmers to clear their fields by burning in preparation for the subsequent short rainy season.

From December to February, the bare land coverage decreases as the rainy season begins. Flooding along the Kilombero River is a periodical event although the extent varies from year to year (Fig. 5). In June, bare land coverage increases due to sediment accumulation following receding waters after the floods. The location of vegetated land cover shifts depending on the season. In the rainy season, areas outside of the riparian zone are vegetated while vegetation coverage within the riparian zone increases in the dry season. The built-up class remains constant with the slight variations due to changes in masked out areas. The road heading to Kilombero River is slightly higher than the surrounding area. During the rainy season, flooding partly submerges this road. As a result, the width of the road varies between the rainy and the dry seasons as seen on the optical images. During the dry season, the road width remains constant and is 

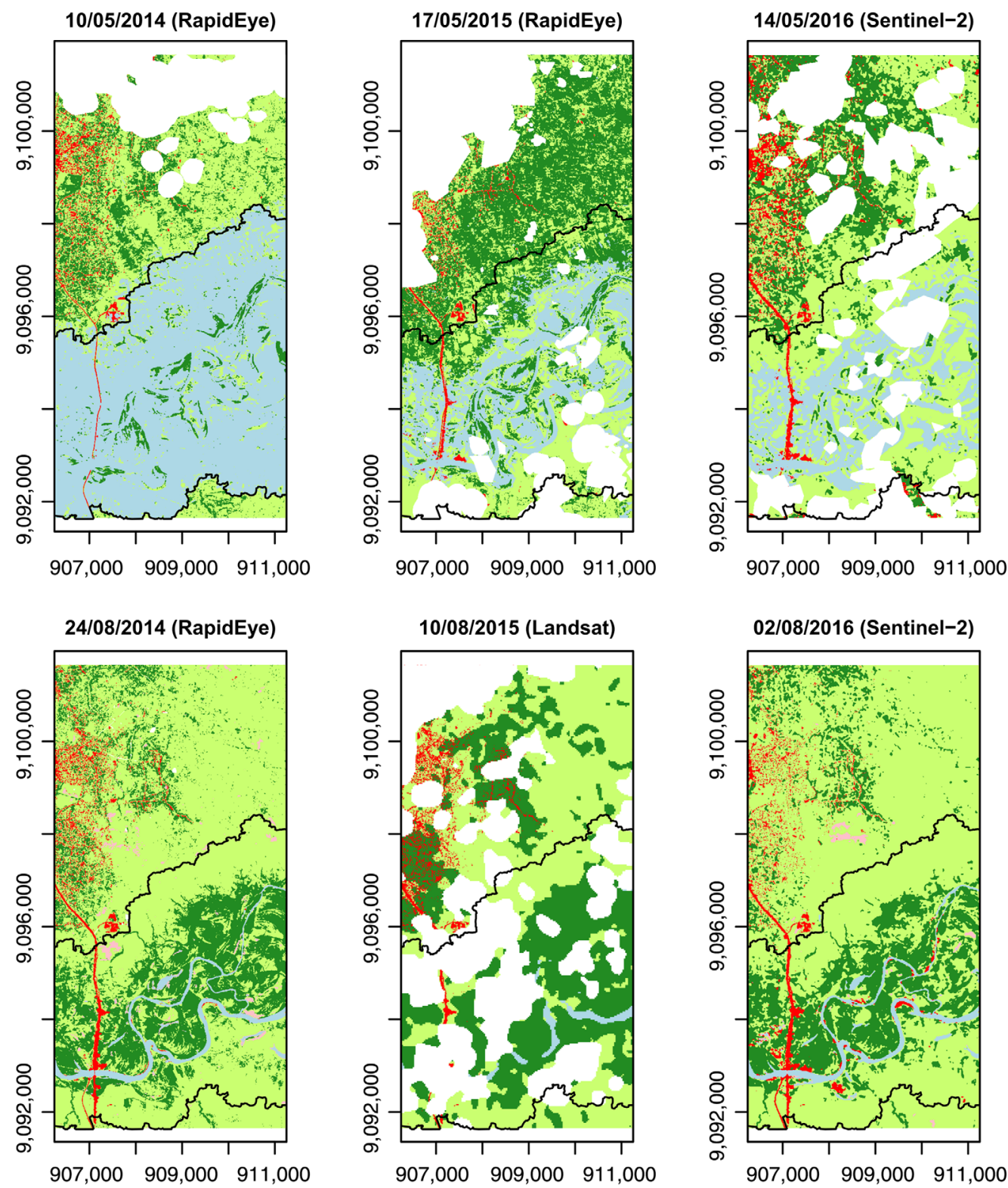

Le end

Bare

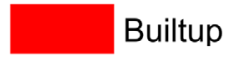

Vegetated

Water

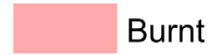

225 m contour

Fig. 5 Classified images of the rainy (May) and dry seasons (August). The masked areas (white) are due to cloud coverage; the 225-m contour line shows the delineated riparian zone. RapidEye has a resolution of $5 \mathrm{~m}$, Sentinel-2 $10 \mathrm{~m}$, and Landsat $30 \mathrm{~m}$.

clearly visible in the optical images. Cloud coverage ultimately prevents that the areas masked out due to clouds and cloud shadows fall in any other class, thus, land cover change analysis was not possible (Fig. 2).

The farmers in the study area mainly practice agriculture dependent on rain. The major land cover in the dry season between June and October is bare. High temperatures and low soil water content attribute to the bare land cover. At the beginning of the rainy season in December, the vegetation cover increases and reaches a peak in May to June (Fig. 5). Areas in the north of the study area not affected by floods are vegetated in this time. Hence, images acquired in May to June indicate that there is vegetation in the northern sections. Images acquired in August indicate 


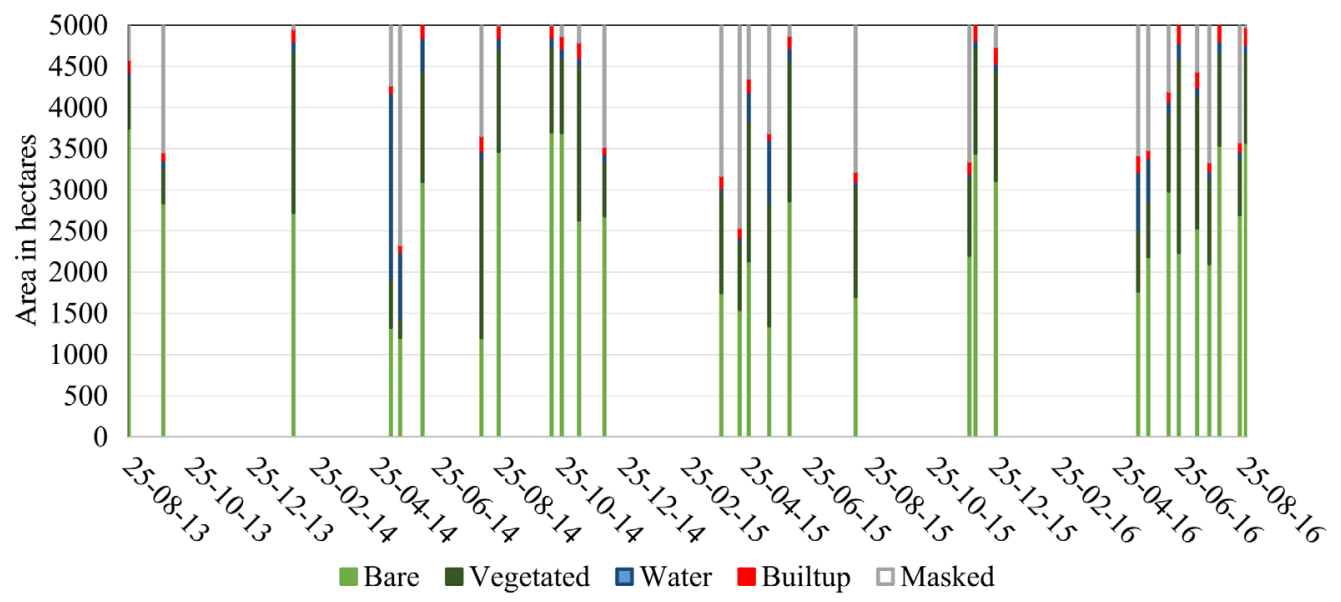

Fig. 6 Areal coverage of land classes in hectares. The spacing between acquisitions indicates the inconsistent optical image availability.

Table 1 Accuracy assessment of the SVM classification.

\begin{tabular}{|c|c|c|c|c|c|c|c|}
\hline Image date & Sensor & $\begin{array}{c}\text { Overall } \\
\text { accuracy }\end{array}$ & $\begin{array}{c}\text { Kappa } \\
\text { coefficients }\end{array}$ & Image date & Sensor & $\begin{array}{l}\text { Overall } \\
\text { accuracy }\end{array}$ & $\begin{array}{c}\text { Kappa } \\
\text { coefficients }\end{array}$ \\
\hline $\begin{array}{l}\text { August 25, } \\
2013\end{array}$ & RapidEye & 93.8 & 0.92 & May 17, 2015 & RapidEye & 81.6 & 0.77 \\
\hline $\begin{array}{l}\text { September } \\
28,2013\end{array}$ & RapidEye & 94.1 & 0.93 & June 6, 2015 & RapidEye & 87.9 & 0.85 \\
\hline $\begin{array}{l}\text { February } 3, \\
2014\end{array}$ & RapidEye & 87.8 & 0.85 & August 10, 2015 & Landsat & 91.0 & 0.88 \\
\hline May 10, 2014 & RapidEye & 93.6 & 0.92 & November 30, 2015 & Landsat & 82.3 & 0.76 \\
\hline May 19,2014 & Landsat & 70.5 & 0.61 & December 6, 2015 & Sentinel-2 & 89.0 & 0.85 \\
\hline $\begin{array}{l}\text { June 10, } \\
2014\end{array}$ & RapidEye & 91.5 & 0.89 & December 26, 2015 & Sentinel-2 & 85.6 & 0.82 \\
\hline $\begin{array}{l}\text { August } 7 \text {, } \\
2014\end{array}$ & Landsat & 90.0 & 0.87 & May 14,2016 & Sentinel-2 & 91.7 & 0.89 \\
\hline $\begin{array}{l}\text { August 24, } \\
2014\end{array}$ & RapidEye & 96.7 & 0.95 & May 24, 2016 & Sentinel-2 & 88.4 & 0.86 \\
\hline $\begin{array}{l}\text { October } 15, \\
2014\end{array}$ & RapidEye & 85.4 & 0.82 & June 13, 2016 & Sentinel-2 & 87.3 & 0.84 \\
\hline $\begin{array}{l}\text { October 25, } \\
2014\end{array}$ & RapidEye & 82.1 & 0.78 & June 23, 2016 & Sentinel-2 & 95.0 & 0.93 \\
\hline $\begin{array}{l}\text { November } \\
11,2014\end{array}$ & Landsat & 86.1 & 0.81 & July 11,2016 & Landsat & 90.8 & 0.88 \\
\hline $\begin{array}{l}\text { December 6, } \\
2014\end{array}$ & RapidEye & 95.6 & 0.94 & July 23, 2016 & Sentinel-2 & 78.9 & 0.74 \\
\hline $\begin{array}{l}\text { March 31, } \\
2015\end{array}$ & RapidEye & 84.9 & 0.81 & August 2, 2016 & Sentinel-2 & 84.3 & 0.8 \\
\hline April 18, 2015 & RapidEye & 92.7 & 0.91 & August 22, 2016 & Sentinel-2 & 79.5 & 0.75 \\
\hline April 27, 2015 & RapidEye & 91.2 & 0.89 & August 28, 2016 & Landsat & 83.3 & 0.78 \\
\hline
\end{tabular}


that the northern parts are bare explained by little or no vegetation since this marks the dry season.

The maximum flooding extent during the rainy season reaches up to $3 \mathrm{~km}$ on both sides of the river as was experienced in May 2014. However, the El Niño phenomenon caused the exceptional flooding (Fig. 5). The flooded zone corresponds to the $225-\mathrm{m}$ contour. The high vegetation coverage in the middle and fringe areas in May and June indicates the presence of suitable conditions to support vegetation growth in areas out of the riparian zone (Fig. 5). The riparian zone has a bare land cover in June due to accumulation of sediments following the rains and subsequent floods.

The pattern of land cover change over the 3 years is consistent and is determined by the seasons. It is evident that with increased precipitation, there is a reduction of bare land cover and an increase in vegetated cover. Consequently, low precipitation results in increased bare cover class (Fig. 7). Knowledge derived from the seasonal land cover thematic maps are a basis for operational monitoring of land conditions, which aid in establishing land management practices to increase agricultural production. Vegetation covers the middle and fringe zones for most of the rainy season. In the dry season, the riparian zone having close proximity to the river is vegetated implying the potential existing in this area for crop production. Conversely, the areas away from the river are bare for most of the dry season. This implies that when it comes to decisions making on land use for increased food production during the dry season, farms in the middle and fringe zones would require additional water supply to produce crops in the dry season.

From the time series of the RapidEye, Landsat, and Sentinel-2 images, frequencies of land cover classes over the entire period were determined (Fig. 8). The bare land cover through the investigated period dominates the areas to the northeast, central, and south of the study area. The region within the riparian zone is frequently vegetated postulating sufficient soil moisture for continued agriculture.

Information from cumulative seasonal maps aid in detailing locations where agricultural improvement mechanisms such as setting up of water pumps and irrigation planning can be spatially located. Areas with a low bare cover detection rate can adopt less cost-effective methods (such as manual pumps) whereas areas such as to the northeast where bare land cover is dominant require permanent methods (such as drip irrigation systems) that ensure constant and continuous availability of water to support vegetation growth (Fig. 8).

The spatial-temporal changes occurring between January to June and July to December are assessed by computing the cumulative season duration maps of each class from the classification maps produced (Fig. 8). Observations indicate an increase in bare cover to the south and northeast in the second half of the year. In the first half of the year, the central and northern regions are

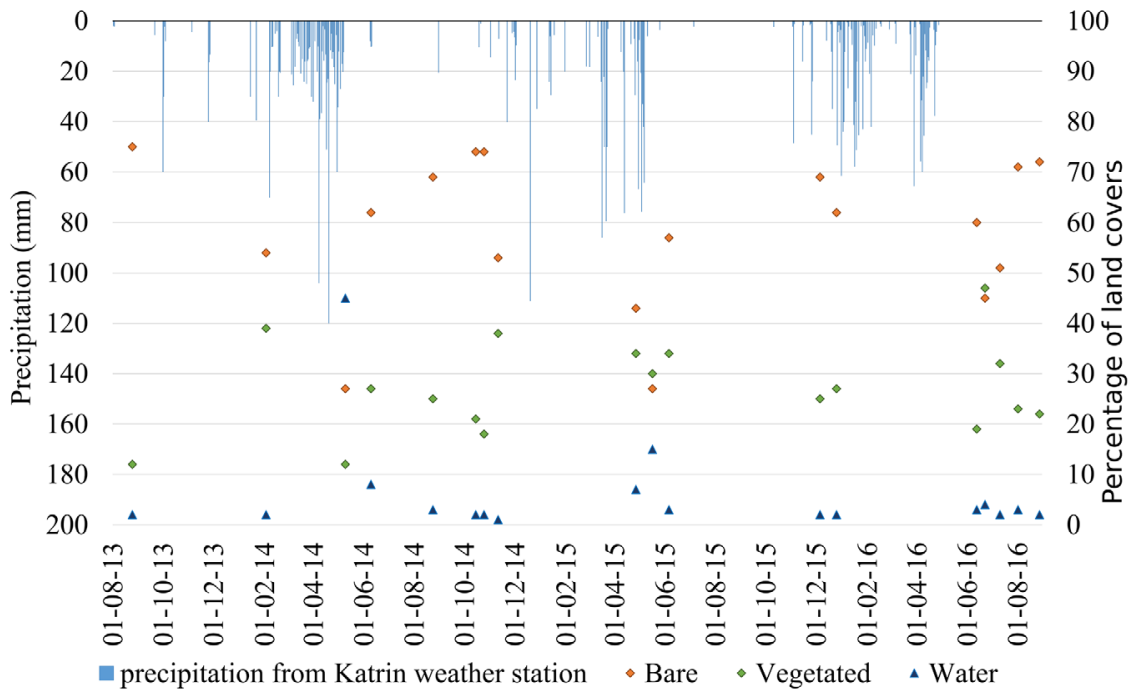

Fig. 7 Relationship of precipitation and percentage of land cover. 

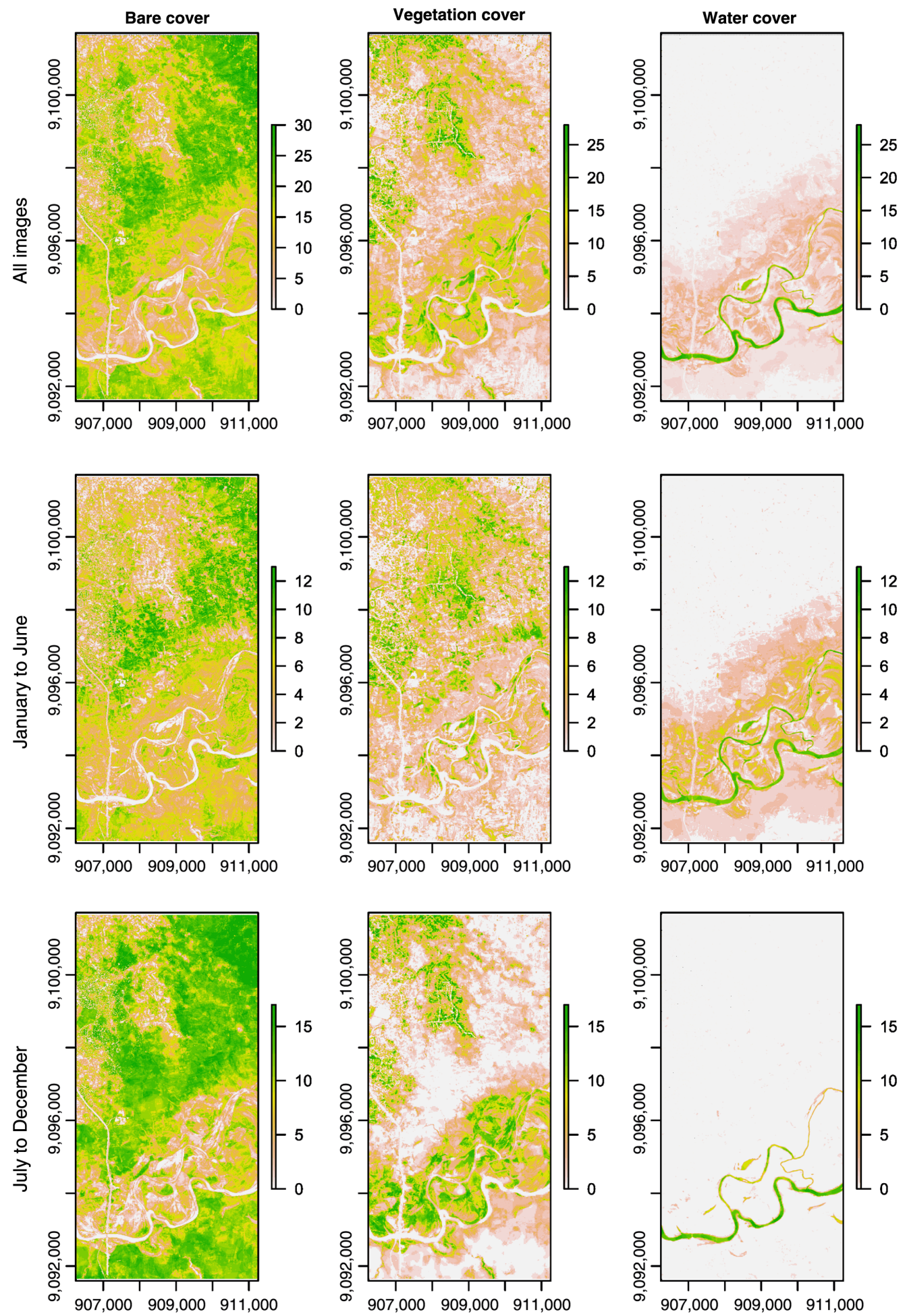

Fig. 8 Detection of (left column) bare cover, (central column) vegetated, and (right column) water for (top row) all images, (central row) rainy season, and (bottom row) dry season. The legend indicates the number of images that generated the cumulative seasonal maps.

vegetated with no vegetation cover observed in these central and northeast regions during the second half of the year. The static structures visible in both the wet and dry season vegetation images located toward the lower north are trees. The extent of water coverage, with maximum extent was observed in May 2014 when there was excessive flooding (Fig. 5). In the second half 
of the year, the water extent is shown to reduce, consistent with the dry season experienced in that time of the year.

Analyzing land cover changes in the riparian zone aided in the understanding of its unique seasonal dynamics due to its proximity to the river. This area covers 2500 ha (half of the total study site). Vegetation increased during the dry season contrary to the areas in the middle and fringe zones. During the rainy season, the riparian zone has less vegetation as compared to the middle and fringe zones because it is largely flooded.

Vegetation within the riparian zone was $>50 \%$ of the total vegetation coverage of the study area from August to October (Fig. 9). High vegetation coverage in the riparian zone in the dry season indicates the presence of a high soil water content capable of supporting the growth of crops. The bare land cover was $>50 \%$ of the total coverage in April to June representative of exposure of sediment accumulation following receding floods in the riparian zone. The results are consistent with a report by Ref. 59 who indicated that rainfed lowland rice is prone to submergence under floods. The receding floods in the riparian zone expose bare land whereby any previously existing vegetation is buried under a layer of silt washed down from the surrounding farms.

Varying yearly flooding patterns in the riparian zone pose a challenge in the determination of planting times. From the results (Fig. 5), a delay in planting time is recommended until the floods recede. In the dry season, the presence of vegetation within the riparian zone infers the agricultural potential of this area. However, in the selection of a suitable crop to plant in the riparian zone during the dry season, factors such as the high temperatures experienced during the dry season should be taken into consideration. ${ }^{60}$

The seasonal land cover dynamics indicates the farmers currently adopt a balance between risk and chance in crop growth. Given the current reports on changing weather patterns, a challenge exists of knowledge on expected flooding patterns. Farmers within the study area take a chance by prepare their fields during the rainy season to maximize the use of the available water for rice plantations. With this opportunity comes the risk of crop loss in case excess flooding destroys the planted rice. Based on the current land cover seasonal maps, forecasting to aid in planning the planting times and spatial locations is recommended.

\subsection{Relationship Between Land Cover and Depth to Groundwater}

The hourly depth to groundwater observations were averaged to daily readings. Table 2 highlights the highest and lowest piezometer readings for the period under study. The riparian zone had the highest recorded value of depth to groundwater $(3.3 \mathrm{~m})$. The lowest depth to groundwater

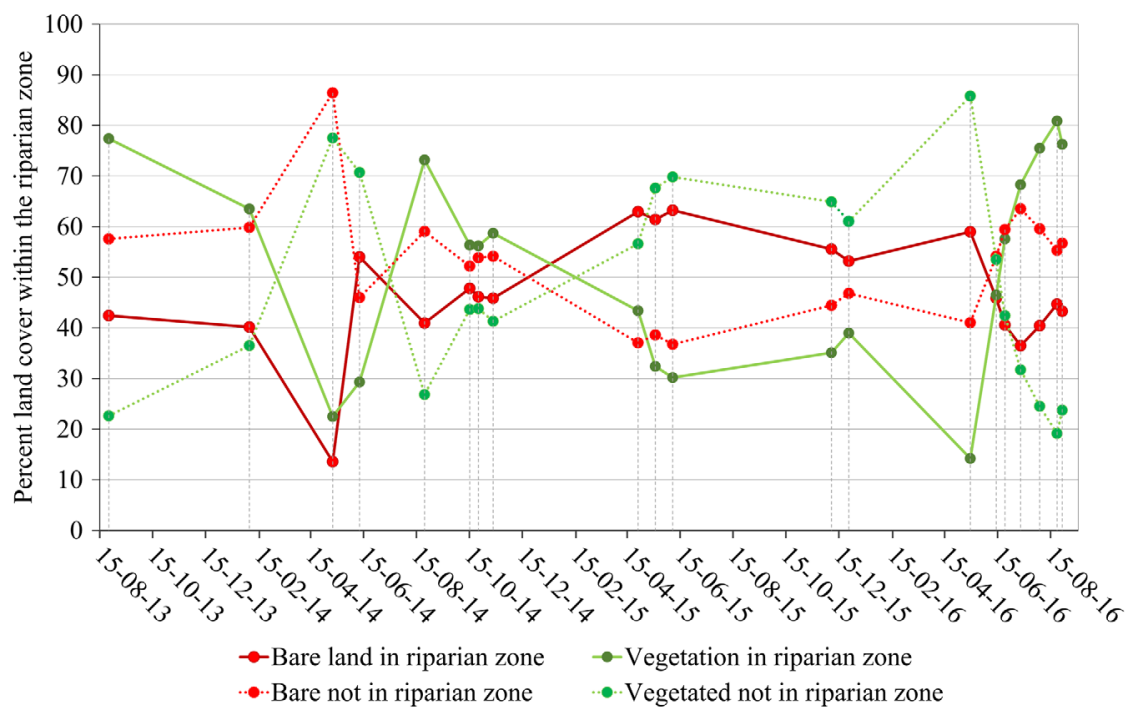

Fig. 9 Percentage of vegetation and bare land cover within the riparian zone as a function of total vegetation and total bare land cover of the study area in percentage. 
Table 2 Piezometer information.

\begin{tabular}{|c|c|c|c|c|}
\hline Name & $\begin{array}{l}\text { Highest } \\
\text { measured } \\
\text { water level }\end{array}$ & $\begin{array}{l}\text { Lowest } \\
\text { measured } \\
\text { water level }\end{array}$ & $\begin{array}{l}\text { Low depth to groundwater } \\
\text { occurrence periods }\end{array}$ & $\begin{array}{l}\text { High depth to groundwater } \\
\text { occurrence periods }\end{array}$ \\
\hline \multirow[t]{3}{*}{ PZ01 } & -1.01 & 3.33 & $>-0.5$ & $<3.0$ \\
\hline & & & April 30 to May 21, 2015 & $\begin{array}{l}\text { October 7, } 2015 \text { to } \\
\text { January 18, } 2016\end{array}$ \\
\hline & & & April 23 to May 14, 2016 & \\
\hline \multirow[t]{4}{*}{ PZ02 } & -2.79 & 1.88 & $>-0.5$ & $<1.5$ \\
\hline & & & April 15 to May 18, 2015 & $\begin{array}{l}\text { October } 18,2015 \text { to } \\
\text { January } 18,2016\end{array}$ \\
\hline & & & January 13 to March 9, 2016 & \\
\hline & & & April 9 to June 3, 2016 & \\
\hline \multirow[t]{3}{*}{ PZ03 } & -3.98 & 1.80 & $>-2.0$ & $<1.5$ \\
\hline & & & April 24 to May 27, 2015 & $\begin{array}{l}\text { August } 26,2015 \text { to } \\
\text { January } 1,2016\end{array}$ \\
\hline & & & $\begin{array}{l}\text { February } 11 \text { to February 28, } 2016 \\
\text { April } 14 \text { to May 30, } 2016\end{array}$ & \\
\hline \multirow[t]{3}{*}{ PZO4 } & -1.94 & 2.50 & $>0.1$ & $<1.5$ \\
\hline & & & January 22 to March 1, 2016 & $\begin{array}{l}\text { August 28, } 2015 \text { to } \\
\text { January 5, } 2016\end{array}$ \\
\hline & & & April 10 to June 1, 2016 & \\
\hline \multirow[t]{3}{*}{ PZ06 } & -0.89 & 2.83 & $>0.1$ & $<2.0$ \\
\hline & & & April 15 to June 9, 2015 & $\begin{array}{l}\text { September } 23,2015 \text { to } \\
\text { January 22, } 2016\end{array}$ \\
\hline & & & April 3 to June 12, 2016 & \\
\hline \multirow[t]{3}{*}{ PZ10 } & -0.08 & 1.30 & $>0.1$ & $<1.0$ \\
\hline & & & March 21 to May 24, 2015 & $\begin{array}{l}\text { September 27, } 2015 \text { to } \\
\text { December 16, } 2015\end{array}$ \\
\hline & & & $\begin{array}{c}\text { January } 20 \text { to February } 26,2016 \\
\text { March } 31 \text { to May } 12,2016\end{array}$ & \\
\hline PZ12 & 3.09 & 3.38 & $\begin{array}{l}\text { Consistently between } 3.15 \text { and } \\
3.25 \text { in June to December } 2015\end{array}$ & $\begin{array}{c}\text { Increased level between } 3.1 \\
\text { and } 3.15 \text { from January to } \\
\text { June } 2016\end{array}$ \\
\hline \multirow[t]{3}{*}{ PZ13 } & 0.20 & 2.35 & $>0.5$ & $<2.0$ \\
\hline & & & April 29 to May 14, 2015 & $\begin{array}{l}\text { October } 27,2015 \text { to } \\
\text { January } 7,2016\end{array}$ \\
\hline & & & $\begin{array}{c}\text { February } 7 \text { to February } 12,2016 \\
\text { April } 6 \text { to May 5, } 2016\end{array}$ & \\
\hline \multirow[t]{3}{*}{ PZ14 } & -0.04 & 2.05 & $>0.2$ & $<1.6$ \\
\hline & & & March 23 to April 21, 2015 & $\begin{array}{l}\text { September } 05,2015 \text { to } \\
\text { January 5, } 2016\end{array}$ \\
\hline & & & $\begin{array}{l}\text { January } 27 \text { to February 23, } 2016 \\
\text { March } 31 \text { to May 9, } 2016\end{array}$ & \\
\hline
\end{tabular}


level at the middle zone was $2.83 \mathrm{~m}$ where that at the fringe was $3.38 \mathrm{~m}$. Negative values stipulate flooding represented by the highest groundwater levels. The highest value was in the riparian zone at $-3.98 \mathrm{~m}$. The middle and fringe zones had -0.89 and $-0.08 \mathrm{~m}$ as the highest values, respectively.

Groundwater depths for the middle and fringe show a similar pattern whereas that of the fringe shows that the water is close to the surface throughout the year (Fig. 10). The fringe receives groundwater from the mountains as base flow while the groundwater level in the riparian and the middle zone depends on the river water level. The depth to groundwater is higher for the riparian zone compared to the middle in the rain season. Rainfall pattern is reflected directly in the fringe piezometers whereas the response in the middle and riparian fields is very little and is delayed. ${ }^{45}$ A steep decrease in depth to ground water is observed in March and January, usually taking between 1 and 2 months to reach a peak. A slight increase in depth to groundwater is observed in February coinciding with the reduced precipitation. An increase in precipitation in March subsequently results in a decrease in depth to ground water. In the dry season, the increase in depth to ground water has a gentle slope taking $\sim 7$ months to reach its lowest level. The precipitation and depth to ground water pattern indicate that the groundwater responds to precipitation patterns. This implies that some portion of the rainwater infiltrates into the ground in rainy seasons resulting to a fast rise in the water level. The rate of rise of the water level (recharge) is faster than the rate at which the depth to groundwater increases (groundwater drains).

Figure 10 presents the ratios of the land cover classes of images with $<10 \%$ cloud cover together with the depth to groundwater. The ratio of areas for the water class remained constant for the images analyzed. Toward the end of May, the depth to groundwater level increased and bare land cover within the riparian zone increased as flooding recedes. The vegetated regions fall in the middle and fringe fields. The groundwater depth at the beginning of December was low ranging from 3.3, 2.7, and 0.9 for the riparian, middle, and fringe zones. The high areal coverage of bare land is a result of the dry season experienced in the preceding months. By the end of December, the depth to groundwater was 3.3, 2.8, and $0.7 \mathrm{~m}$. Despite the lower groundwater toward the end of December, vegetation cover increased, attributed to the occurrence of precipitation. In June 2016, depth to groundwater was $1.26,0.36$, and 0.38 for the riparian, middle, and fringe zones. Comparing the vegetated and bare cover of 2015 and 2016, it is evident that the

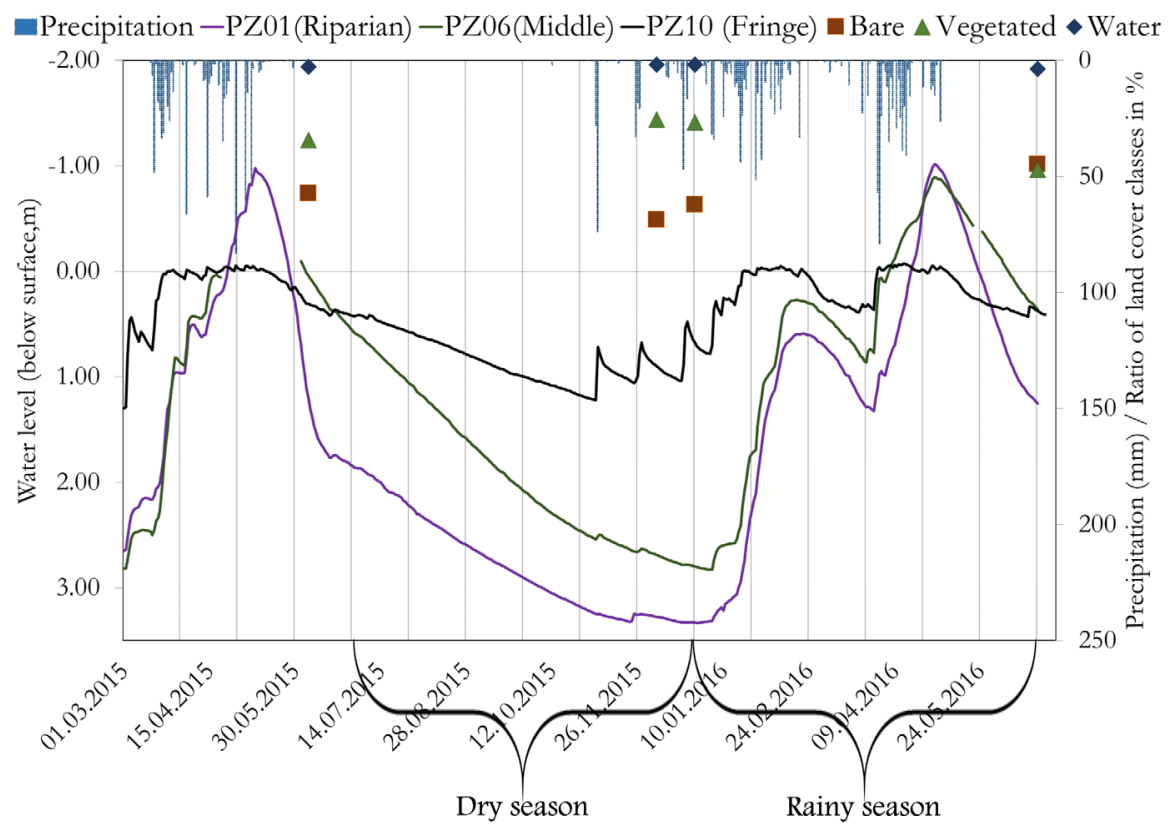

Fig. 10 Groundwater depths in the riparian (PZ 01), middle (PZ 06), and fringe (PZ 10) zones and the corresponding ratios of land cover. The effects of changes in precipitation and temperature on depth to groundwater levels are shown. 


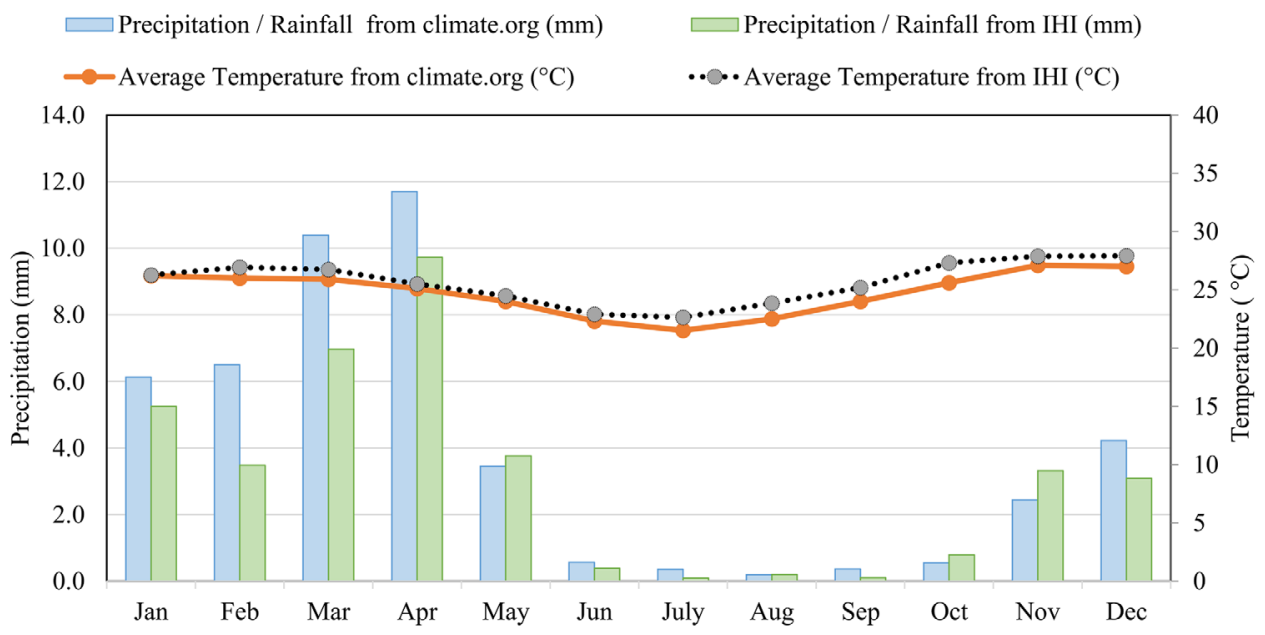

Fig. 11 Comparison of climate data from IHI and climate data for Ifakara.

vegetated coverage in 2016 is higher due to earlier recession of flooding water in 2016. In 2015, the decrease in depth to groundwater level began on May 27 for the Riparian and May 15 for the fringe. However, in 2016, the decline began on May 23 in the Riparian zone and May 6 in the fringe zone. Saturated soils had drained excess water by June 23, 2016 and hence the soil water content was suitable to support vegetation growth. The results show that the land covers respond to depths to groundwater.

Climate influences groundwater via precipitation infiltration and evapotranspiration rates depending on temperature ${ }^{31}$ Comparison of the precipitation data from the IHI station and climate data in Ifakara ${ }^{61}$ indicate that average temperatures are similar as shown in Fig. 11. Precipitation recorded at IHI is, however, slightly lower by $\sim 1.2 \mathrm{~mm} /$ day. Increased precipitation reduces the depth to groundwater, occurring between March and April 2015 and October 2014 to April 2016 (Fig. 12). A moving average trend line indicates that the highest temperature recorded, between May and August, resulted in a decrease in groundwater level. High temperatures as a proxy of high evapotranspiration rates affect shallow groundwater as reported in Ref. 62. Consequently, the high temperature period results in a decrease in groundwater level. Lower temperatures, occurring between October and December 2015 in the rainy season, result in a rise in groundwater level. Another episode of low temperature between February and April 2016 subsequently resulted to a rise in groundwater level. Both temperature and precipitation influence the groundwater levels in the study area.

Point groundwater information are not sufficient to explain the spatial pattern of the land cover image and hence, application of kriging interpolation method on the observed groundwater levels generated groundwater maps containing information at sampled and nonsampled locations. Variogram parameters that generated the kriged images are shown in Table 3. The depth to groundwater patterns from March 2015 to June 2016 are shown in Fig. 12.

The degree of spatial dependence for the groundwater depth raster images generated indicated that in the second half of the year (July to December) had data has a low spatial correlation, i.e., spatial dependence (Table 3). There was a high correlation for the groundwater depths observed in the first half of the year. From this analysis, it is evident that during the dry season when the groundwater level is low, there is a low spatial correlation of the groundwater level measured at the piezometers distributed in the study area. During the first half of the year, the groundwater depth rises and a strong spatial dependence is evidenced. Figure 10 shows the pattern of groundwater depth over the study period.

Depth to groundwater reduces in March and a further reduction in depth is observed in May (Fig. 12). From July to December, the depth to groundwater increases, within this time a vast amount of land has bare cover and there is a rare occurrence of precipitation (Figs. 10 and 12). With the onset of the rains in December, the depth to groundwater is observed to increase from January to June, with the peak observed in the riparian region in April and May. The negative 

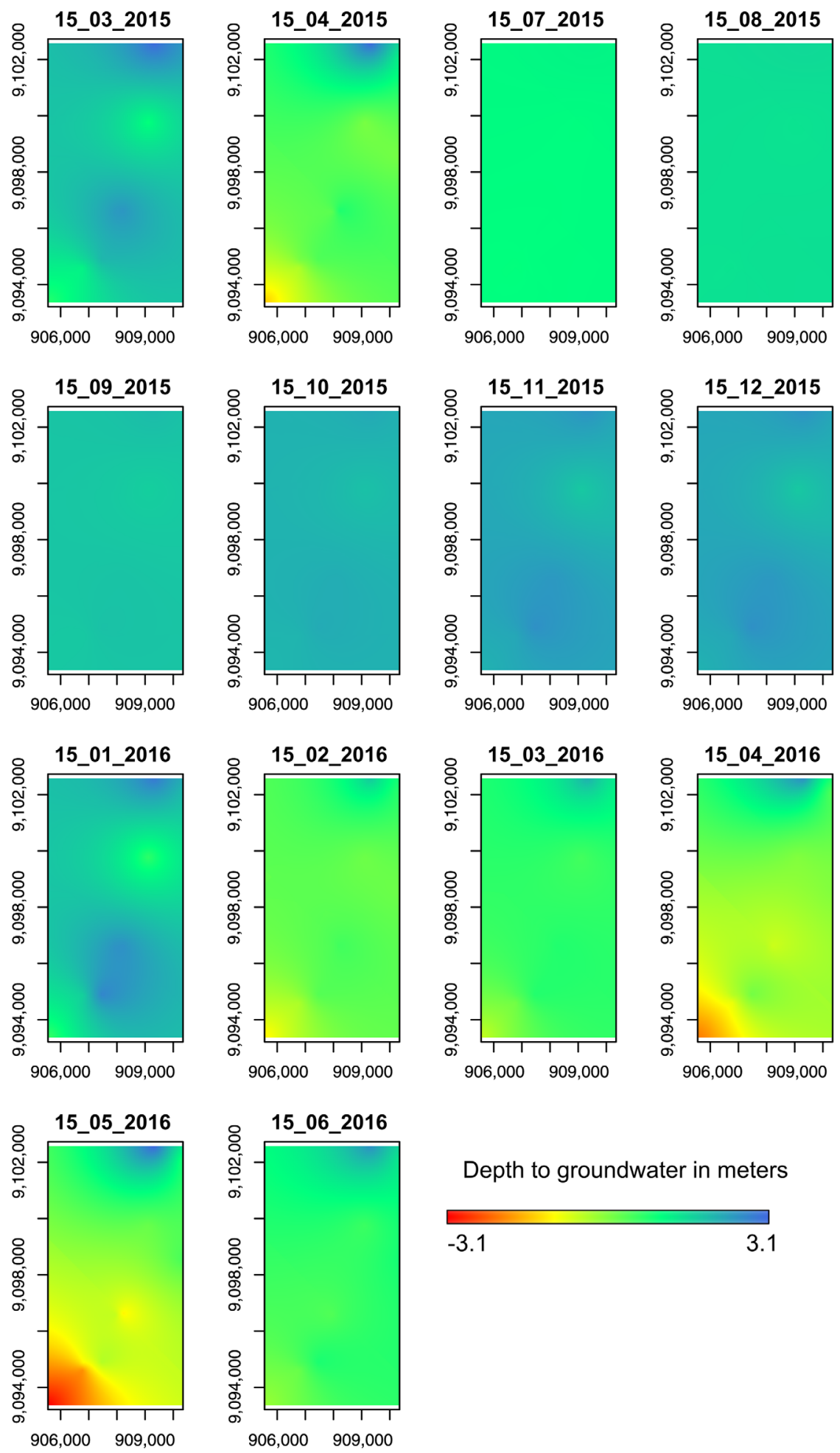

Depth to groundwater in meters

$-3.1$

3.1

Fig. 12 Groundwater levels interpolated using the kriging method and changes in groundwater level between 2015 and 2016. Negative values indicate flooding.

depth to groundwater portrays flooding (Fig. 12). The flooding is observed to commence on the southwestern side of the study area. There is a reduction in bare class and an increase in vegetated land cover from January to June.

The areas, particularly to the south of the study area, have a higher rise in water level as opposed to the northern parts of the study area. The Kilombero River drives the groundwater 
Table 3 Variogram model parameters used for kriging.

\begin{tabular}{lccccc}
\hline \hline Dates & Model & $\begin{array}{c}\text { Nugget } \\
\text { variance }\end{array}$ & Sill & $\begin{array}{c}\text { Degree of spatial } \\
\text { dependence (\%) }\end{array}$ & Range \\
\hline March 15, 2015 & Exponential & 0.2 & 0.9 & 17.0 & 5199.1 \\
April 15, 2015 & Exponential & 0.1 & 0.9 & 6.3 & 6498.7 \\
July 15, 2015 & Exponential & 1.0 & 0.1 & 88.2 & 10469.0 \\
August 15, 2015 & Exponential & 1.0 & 0.1 & 88.1 & 10469.0 \\
September 15, 2015 & Exponential & 0.9 & 0.2 & 84.1 & 5199.1 \\
October 15, 2015 & Exponential & 1.0 & 0.2 & 79.6 & 5199.1 \\
November 15, 2015 & Exponential & 0.7 & 0.5 & 60.0 & 5199.1 \\
December 15, 2015 & Exponential & 0.9 & 0.4 & 67.8 & 5199.1 \\
January 15, 2016 & Exponential & 0.3 & 1.1 & 19.4 & 5199.1 \\
February 15, 2016 & Exponential & 0.3 & 0.7 & 32.1 & 4957.1 \\
March 15, 2016 & Exponential & 0.3 & 0.7 & 27.3 & 5199.1 \\
April 15, 2016 & Exponential & 0.1 & 1.6 & 6.8 & 10412.4 \\
May 15, 2016 & Exponential & 0.0 & 1.3 & 0.0 & 9193.2 \\
June 15, 2016 & Exponential & 0.3 & 1.5 & 15.3 & 8803.3 \\
\hline \hline
\end{tabular}

in the southern part whereas lateral flow from the Udzungwa Mountains drives the groundwater in northern part. ${ }^{45}$ Floods are variable and discernable on the optical images. Lateral flow is deep-seated and more stable.

The current study showed that a link exists between land cover and depth of groundwater. High groundwater depths result in a high percentage of vegetated land cover class whereas bare land cover class mainly occurs in low groundwater depths and after flooding events. However, in the riparian zone, despite a high depth to groundwater in the dry season, vegetation thrived due to the high soil moisture availability caused by a high clay content.

A more detailed assessment of thematic land cover was not possible due to the limited number of cloud-free images. Differentiation of crop types and mapping of the field boundaries was not possible due to the highly fragmented farm sizes and high variability of crops grown. Furthermore, the limited number of matching cloud-free images and groundwater level restricted the analysis of the relationship between land cover and groundwater water depth. To capture the field boundaries, very high-resolution imagery is required. In addition, for future research, the use of radar data will ensure consistent high temporal land cover mapping to capture the land cover dynamics that are not captured by optical images as the radar data are independent of effects from weather conditions and are thus not affected by the presence of cloud coverage.

\section{Conclusions}

The results of this study allow a better understanding of the land cover dynamics within the Kilombero River floodplain near Ifakara, Tanzania. We generated land cover maps and cumulative seasonal land cover maps that depict the variation in land cover distribution over time. These dynamics are largely driven by water availability as a result of strong rainfall during the rainy season. We further investigated the dynamics of land cover and depth to groundwater at three hydrological zones. The first major finding was that in the rainy season, groundwater level is high, and a large amount of land in the middle and riparian zone are vegetated. The riparian zone is flooded with a maximum observed extent of $3 \mathrm{~km}$ on both sides of the river during the El Niño rains in 2014. However, the flooding intensities vary from year to 
year. The second major finding was that in the dry season, groundwater level is low, the area within the riparian zone is vegetated, and the other zones are mainly bare. The availability of soil moisture supporting vegetation growth in the margins of the riparian zone indicates that the moisture in soils emanates from the water in the Kilombero River. The high proportion of vegetated areas in the middle and fringe zones during the rainy season points to the good moisture conditions, which favor crop growth. Most sections of the riparian zone are classified as bare after the rainy season due to accumulation of soil sediments. The cumulative seasonal maps reveal low vegetation coverage in the central and northeast regions of the study area. Groundwater responds to precipitation and the rate of groundwater recharge is higher than the rate of draining.

This research enhanced our understanding of land cover changes and their role in agricultural production in rainfed agricultural systems by providing spatiotemporal explicit land use information. Seasonal land cover information will help in land use planning with respect to suitable crops and farming practices that could lead to increased yield and therefore an increase in food security. Future studies investigating the economic capability of the farmers and agricultural development research institutions to adopt climate-smart agriculture are recommended. Continued monitoring is recommended to assess the impact of adopted technologies on agricultural yields. The effect of land use on groundwater quality should be assessed in the face of increasing pressure on water demands as it forms an additional source of water for the growing population and therefore any contamination points should be controlled and halted.

\section{Disclosure}

The author declares no conflict of interest.

\section{Acknowledgments}

The authors are grateful to the Federal Ministry of Education and Research (BMBF) for funding the research under the project BMBF FKZ.031A250A-H under the GlobE wetlands in East Africa project. We also acknowledge BlackBridge for providing the RapidEye images in the Project No. 660. We acknowledge the contribution of the late Professor Gunter Menz for his guidance at the start of this research. We are grateful to the Remote Sensing Research Group and all the reviewers who supported and gave helpful comments.

\section{References}

1. N. Alexandratos and J. Bruinsma, "World agriculture towards 2030/2050: the 2012 revision," ESA Working Paper Rome, FAO (2012).

2. Food and Agriculture Organization of the United Nations, Climate-Smart Agriculture Sourcebook, Food and Agriculture Organization of the United Nations, Rome, Italy (2014).

3. E. K. Vizy et al., "Projected changes in Malawi's growing season," Clim. Dyn. 45(5-6), 1673-1698 (2015).

4. P. Peltonen-Sainio, L. Jauhiainen, and K. Hakala, "Climate change and prolongation of growing season: changes in regional potential for field crop production in Finland," Agric. Food Sci. 18(3-4), 171 (2008).

5. R. Shetto et al., Eds., Conservation Agriculture as Practised in Tanzania: Three Case Studies, African Conservation Tillage Network; Food Agriculture Organization of the United Nations, Nairobi: Centre de Coopération international de recherche agronomique pour le développement; Rome, Italy (2007).

6. D. Le Blanc, "Towards integration at last? The sustainable development goals as a network of targets," Sustain. Dev. 23(3), 176-187 (2015).

7. F. Kato, "Development of a major rice cultivation area in the Kilombero Valley, Tanzania," Afr. Study Monogr. (36), 3-18 (2007). 
8. A. D. Beck, "The Kilombero valley of south-central Tanganyika," East Afr. Geogr. Rev. 1964(2), 37-43 (1964).

9. J. U. H. Eitel et al., "Broadband, red-edge information from satellites improves early stress detection in a New Mexico conifer woodland," Remote Sens. Environ. 115(12), 3640-3646 (2011).

10. H. A. Seki et al., "The impact of land use and land cover change on biodiversity within and adjacent to Kibasira Swamp in Kilombero Valley, Tanzania," Afr. J. Ecol. (2017).

11. C. O. Justice, B. N. Holben, and M. D. Gwynne, "Monitoring East African vegetation using AVHRR data," Int. J. Remote Sens. 7(11), 1453-1474 (1986).

12. B. Haack, "Monitoring wetland changes with remote sensing: an East African example," Environ. Manage. 20(3), 411-419 (1996).

13. S. Serneels, M. Y. Said, and E. F. Lambin, "Land cover changes around a major east African wildlife reserve: the Mara Ecosystem (Kenya)," Int. J. Remote Sens. 22(17), 3397-3420 (2001).

14. L. M. Kiage et al., "Recent land-cover/use change associated with land degradation in the Lake Baringo catchment, Kenya, East Africa: evidence from Landsat TM and ETM+," Int. J. Remote Sens. 28(19), 4285-4309 (2007).

15. W. A. Ntongani et al., "Local knowledge on the influence of land use/cover changes and conservation threats on Avian Community in the Kilombero Wetlands, Tanzania," Open J. Ecol. 4(12), 723-731 (2014).

16. C. Leemhuis et al., "Sustainability in the food-water-ecosystem nexus: the role of land use and land cover change for water resources and ecosystems in the Kilombero Wetland, Tanzania," Sustainability 9(9), 1513 (2017).

17. SAGCOT, "Southern Agricultural Growth Corridor of Tanzania: Concept Note," 2017, http://sagcot.co.tz/ (June 2017).

18. J. Milder et al., A Framework for Agriculture Green Growth: Greenprint for the Southern Agricultural Growth Corridor of Tanzania (SAGCOT), SAGCOT Centre, Dar Es Salaam, Tanzania (2013).

19. D. N. Lerner and B. Harris, "The relationship between land use and groundwater resources and quality," Land Use Policy 26, S265-S273 (2009).

20. A. Prabhakar and H. Tiwari, "Land use and land cover effect on groundwater storage," Model. Earth Syst. Environ. 1(4) (2015).

21. Y. Pan et al., "Impact of land use change on groundwater recharge in Guishui River Basin, China," Chin. Geogr. Sci. 21(6), 734-743 (2011).

22. B. R. Scanlon et al., "Impact of land use and land cover change on groundwater recharge and quality in the southwestern US," Global Change Biol. 11(10), 1577-1593 (2005).

23. Y. K. Zhang and K. E. Schilling, "Effects of land cover on water table, soil moisture, evapotranspiration, and groundwater recharge: a field observation and analysis," J. Hydrol. 319(1-4), 328-338 (2006).

24. R. G. Taylor et al., "Ground water and climate change," Nat. Clim. Change 3(4), 322-329 (2012).

25. S. O. Owuor et al., "Groundwater recharge rates and surface runoff response to land use and land cover changes in semi-arid environments," Ecol. Process. 5(1) (2016).

26. D. Rodriguez et al., "Detection of nitrogen deficiency in wheat from spectral reflectance indices and basic crop eco-physiological concepts," Aust. J. Agric. Res. 57(7), 781 (2006).

27. M. Schönert et al., "The tasseled cap transformation for RapidEye data and the estimation of vital and senescent crop parameters," Int. Arch. Photogramm. Remote Sens. Spat. Inf. Sci. 101-108 (2015).

28. G. Mountrakis, J. Im, and C. Ogole, "Support vector machines in remote sensing: a review," ISPRS J. Photogramm. Remote Sens. 66(3), 247-259 (2011).

29. J. Paneque-Gálvez et al., "Enhanced land use/cover classification of heterogeneous tropical landscapes using support vector machines and textural homogeneity," Int. J. Appl. Earth Obs. Geoinf. 23, 372-383 (2013).

30. B. Tso and P. M. Mather, Classification Methods for Remotely Sensed Data, 2nd ed., CRC Press, Boca Raton, Florida (2009). 
31. X. Li, G. Li, and Y. Zhang, "Identifying major factors affecting groundwater change in the North China plain with grey relational analysis," Water 6(6), 1581-1600 (2014).

32. S. Burghof et al., "Development of a hydrogeological conceptual wetland model in the datascarce north-eastern region of Kilombero Valley, Tanzania," Hydrogeol. J. (2017).

33. Uni Bonn, "A GlobE Initiative for 'Global Food Security," 2014, https://www. wetlands-africa.uni-bonn.de/ (May 2015).

34. A. J. Koutsouris, D. Chen, and S. W. Lyon, "Comparing global precipitation data sets in eastern Africa: a case study of Kilombero Valley, Tanzania: comparing global precipitation data sets in Tanzania, East Africa," Int. J. Climatol. 36(4), 2000-2014 (2016).

35. S. B. Siima et al., "Estimating direct use value of Kilombero Ramsar site based on market price method," Tanzan. J. For. Nat. Conserv. 81(2), 133-146 (2012).

36. S. Daniel et al., "Spatial distribution of soil hydrological properties in the Kilombero floodplain, Tanzania," Hydrology 4(4), 57 (2017).

37. "Planet," 29 September 2016, https://planet.com/ (2 October 2016).

38. ESA Sentinels Scientific Data Hub, https://scihub.copernicus.eu/dhus/\#/home (2 October 2016).

39. M. Drusch et al., "Sentinel-2: ESA's optical high-resolution mission for GMES operational services," Remote Sens. Environ. 120, 25-36 (2012).

40. USGS, "Earth Explorer Landsat Website," 2017, https://earthexplorer.usgs.gov/ (June 2016).

41. J. Barsi et al., "The spectral response of the Landsat-8 operational land imager," Remote Sens. 6(10), 10232-10251 (2014).

42. C. Schuster, M. Förster, and B. Kleinschmit, "Testing the red edge channel for improving land-use classifications based on high-resolution multi-spectral satellite data," Int. J. Remote Sens. 33(17), 5583-5599 (2012).

43. E. Adam, O. Mutanga, and D. Rugege, "Multispectral and hyperspectral remote sensing for identification and mapping of wetland vegetation: a review," Wetlands Ecol. Manage. 18(3), 281-296 (2010).

44. Garmin International, "Garmin eTrex Series," 2005, https://www8.garmin.com/specs/ eTrex_spec_sheet_0105.pdf (June 2017).

45. G. Gabiri et al., "Modeling spatial soil water dynamics in a tropical floodplain, East Africa," Water 10(2), 191 (2018).

46. R. Richter and D. Schläpfer, Atmospheric/Topographic Correction for Satellite Imagery (ATCOR-2/3 User Guide, Version 8.3. 1, February 2014), ReSe Applications Schläpfer Langeggweg 3 (2013).

47. J. R. Nagol et al., "Bidirectional effects in Landsat reflectance estimates: is there a problem to solve?" ISPRS J. Photogramm. Remote Sens. 103, 129-135 (2015).

48. E. Vaudour et al., "Spatial retrieval of soil reflectance from SPOT multispectral data using the empirical line method," Int. J. Remote Sens. 29(19), 5571-5584 (2008).

49. Z. Zhu, S. Wang, and C. E. Woodcock, "Improvement and expansion of the Fmask algorithm: cloud, cloud shadow, and snow detection for Landsats 4-7, 8, and sentinel 2 images," Remote Sens. Environ. 159, 269-277 (2015).

50. A. Chatziantoniou, G. P. Petropoulos, and E. Psomiadis, "Co-Orbital Sentinel 1 and 2 for LULC mapping with emphasis on wetlands in a Mediterranean setting based on machine learning," Remote Sens. 9(12), 1259 (2017).

51. R. Pande-Chhetri et al., "Object-based classification of wetland vegetation using very high-resolution unmanned air system imagery," Eur. J. Remote Sens. 50(1), 564-576 (2017).

52. S. van der Linden et al., "The EnMAP-Box: a toolbox and application programming interface for EnMAP data processing," Remote Sens. 7(9), 11249-11266 (2015).

53. R. G. Congalton and K. Green, Assessing the Accuracy of Remotely Sensed Data: Principles and Practices, 2nd ed., CRC Press/Taylor \& Francis, Boca Raton, Florida (2009).

54. J. R. B. Fisher et al., "Impact of satellite imagery spatial resolution on land use classification accuracy and modeled water quality," Remote Sens. Ecol. Conserv. (2017).

55. T. Hengl, A Practical Guide to Geostatistical Mapping, 2nd ed., Hengl, Amsterdam (2009). 
56. T. Hengl et al., A Practical Guide to Geostatistical Mapping of Environmental Variables, Publications Office, Luxembourg (2007).

57. J. A. Rodríguez Martín et al., "Assessment of the soil organic carbon stock in Spain," Geoderma 264, 117-125 (2016).

58. L. Jing et al., "Spatial variability analysis of soil nutrients based on GIS and geostatistics: a case study of Yisa Township, Yunnan, China," J. Resour. Ecol. 5(4), 348-355 (2014).

59. T. Wilson and I. Lewis, "The Rice Value Chain in Tanzania - A Report From the Southern Highlands Food Systems Programme (FAO)," 2015, http://www.fao.org/sustainable-foodvalue-chains/library/details/en/c/285411/ (October 2017).

60. A. Nicol et al., Water-Smart Agriculture in East Africa, IWMI, Colombo, Sri Lanka (2015).

61. En.climate-data.org, "Climate :Ifakara," https://en.climate-data.org/location/26417/ (May 2017).

62. N. N. Ndou, L. G. Palamuleni, and A. Ramoelo, "Modelling depth to groundwater level using SEBAL-based dry season potential evapotranspiration in the upper Molopo River Catchment, South Africa," Egypt. J. Remote Sens. Space Sci. (2017).

Fridah Kirimi is a doctoral student in the Remote Sensing Research Group (RSRG), Bonn University, Germany. Her research interests are remote sensing techniques land cover mapping in the East African wetlands. She has interests in both optical and SAR remote sensing.

Kuria Thiong'o is a doctoral student in Geomatics Research Group, Bochum University, Germany. His research interests are remote sensing applications in agriculture toward food security.

Geofrey Gabiri is a doctoral student in the Hydrology Research Group (HRG), University of Bonn Germany. His research interests are sustainable agriculture and water resource management.

Bernd Diekkrüger is a professor and the head of the HRG at the Department of Geography, University of Bonn, Germany. His research interests include analyzing and modeling hydrological processes at different spatial and temporal scales including impact of climate and land use and land cover change.

Frank Thonfeld is a postgraduate senior researcher in the RSRG, Bonn University, Germany. His research mainly focuses on optical and SAR remote sensing in wetland mapping. 